\title{
Development of Ramulosis Disease of Cotton Under Controlled Environment and Field Conditions
}

\author{
José Eduardo B. A. Monteiro, Paulo C. Sentelhas, Mark L. Gleason, Paul D. Esker, and Ederaldo J. Chiavegato
}

First and second authors: Agrometeorology Group, Department of Exact Sciences, ESALQ, University of São Paulo, P.O. Box 9, 13418-900 Piracicaba, SP, Brazil; third author: Department of Plant Pathology, Iowa State University, Ames 50011; fourth author: Department of Plant Pathology, University of Wisconsin, Madison 53706; and fifth author: Department of Plant Production, ESALQ, University of São Paulo.

Accepted for publication 27 November 2008.

\begin{abstract}
Monteiro, J. E. B. A., Sentelhas, P. C., Gleason, M. L., Esker, P. D., and Chiavegato, E. J. 2009. Development of ramulosis disease of cotton under controlled environment and field conditions. Phytopathology 99:659-665.

Colletotrichum gossypii var. cephalosporioides, the fungus that causes ramulosis disease of cotton, is widespread in Brazil and can cause severe yield loss. Because weather conditions greatly affect disease development, the objective of this work was to develop weather-based models to assess disease favorability. Latent period, incidence, and severity of ramulosis symptoms were evaluated in controlled environment experiments using factorial combinations of temperature $(15,20,25,30$, and $\left.35^{\circ} \mathrm{C}\right)$ and leaf wetness duration $(0,4,8,16,32$, and $64 \mathrm{~h}$ after inoculation). Severity was modeled as an exponential function of leaf

periods were increased from 4 to $32 \mathrm{~h}$. In field experiments at Piracicaba, São Paulo State, Brazil, cotton plots were inoculated $\left(10^{5}\right.$ conidia $\left.\mathrm{ml}^{-1}\right)$ and ramulosis severity was evaluated weekly. The model obtained from the controlled environment study was used to generate a disease favorability index for comparison with disease progress rate in the field. Hourly measurements of solar radiation, temperature, relative humidity, leaf wetness duration, rainfall, and wind speed were also evaluated as possible explanatory variables. Both the disease favorability model and a model based on rainfall explained ramulosis growth rate well, with $R^{2}$ of 0.89 and 0.91 , respectively. They are proposed as models of ramulosis development rate on cotton in Brazil, and weather-disease relationships revealed by this work can form the basis of a warning system for ramulosis development.
\end{abstract} wetness duration and temperature. At the optimum temperature of disease development, $27^{\circ} \mathrm{C}$, average latent period was 10 days. Maximum ramulosis severity occurred from 20 to $30^{\circ} \mathrm{C}$, with sharp decreases at lower and higher temperatures. Ramulosis severity increased as wetness
Additional keywords: disease forecasting system, Gossypium hirsutum, witches'-broom.
Cotton (Gossypium hirsutum L.) ramulosis caused by Colletotrichum gossypii (South) var. cephalosporioides (A. S. Costa) occurs throughout Brazil, Venezuela, and Paraguay. Ramulosis, also known as witches'-broom, is currently considered the most important disease of cotton in Brazil. Without an effective fungicide spray program, severe yield losses may occur $(5,19,25)$. Cotton is commercially cultivated in more than 65 countries, on about 34.4 million hectares. Cotton fiber constitutes more than $40 \%$ of clothing worldwide, including $60 \%$ in Brazil and $65 \%$ in the United States (11).

Ramulosis symptoms appear on leaves, petioles, and branches as nearly circular necrotic spots. Infected leaf tissue drops from the plant, causing an irregular shot-hole varying from 1 to $10 \mathrm{~mm}$ in diameter. Later, C. gossypii var. cephalosporioides may cause necrosis of the apical meristem, triggering development of lateral sprouts that resemble witches'-brooms and causing stunting (5, 19). Dispersal of C. gossypii var. cephalosporioides is typically via seeds that are contaminated externally by conidia or internally by dormant mycelia. The pathogen can also survive several years in contaminated soil (32).

Fungicide sprays are a necessary part of ramulosis management because most producers plant susceptible cultivars due to market demand for them (5). Consequently, a disease forecasting system, if developed, could offer cotton producers a

Corresponding author: J. E. B. A. Monteiro; E-mail address: agro.project@gmail.com

doi:10.1094/PHYTO-99-6-0659

(c) 2009 The American Phytopathological Society strategy to assess disease risk and possibly reduce the frequency of fungicide sprays.

Disease-warning systems have increasingly become important tools for improving crop disease management. An essential component of most disease-warning systems is assessment of disease progress favorability, usually related to weather conditions. A favorability index is the ratio, derived from a model fitted on series of observed facts, that reveal how much specific weather variables promote or facilitate the development of a given plant disease. The model describes favorability of weather as a proportion ( 0.0 to 1.0$)$ of the maximum possible infection level set by host and inoculum, under controlled conditions $(1,21,22)$.

While much is known regarding the biology of ramulosis infection in cotton $(6,17,23,28,29)$, relationships between environmental conditions and ramulosis epidemics have not been evaluated. Because temperature and leaf wetness duration (LWD) often impact the risk of foliar disease epidemics $(8,10)$, they were assumed to be logical starting points in assessing environmentdisease interactions in ramulosis.

The main objectives of this study were to (i) determine relationships of temperature and LWD to ramulosis infection in order to develop a disease favorability index, and (ii) in field experiments, evaluate the favorability index in conjunction with other meteorological variables.

\section{MATERIALS AND METHODS}

Controlled environment experiments. Growth chamber trials were performed to determine temperature and LWD optima for infection of cotton by $C$. gossypii var. cephalosporioides. 
Isolates of C. gossypii var. cephalosporioides obtained in São Paulo State, Brazil, from naturally infected cotton plants were raised on oat media at $26^{\circ} \mathrm{C}$ in growth chambers under continuous darkness. Conidia from 21-day-old cultures were dislodged using a sterile glass slide and suspended in sterile distilled water. The conidial suspension was then filtered and conidial concentration was determined using a hemacytometer. The conidial suspension was diluted with sterile distilled water to obtain a final concentration of $10^{5}$ conidia $\mathrm{ml}^{-1}(3)$.

Cotton seeds (cv. Makina, Syngenta Seeds, São Paulo, SP, Brazil) were planted outdoors in plastic pots $(15 \mathrm{~cm}$ diameter $)$ containing soil, vermiculite, and peat in a $2: 1: 1(\mathrm{vol} / \mathrm{vol} / \mathrm{vol}) \mathrm{mix}-$ ture. Plants were inoculated 21 days after emergence (DAE) when they had four fully expanded leaves and were starting to unfold the fifth leaf. A hand sprayer was used to deliver the conidial suspension to adaxial leaf surfaces, petioles, and stems of each group of 36 plants. Care was taken to apply inoculum uniformly until runoff.

After inoculation, four groups of 36 plants each were randomly assigned to growth chambers maintained at $15,20,25$, or $30^{\circ} \mathrm{C}$ and a light period of $12 \mathrm{~h}$. For each temperature, six subgroups of six plants each were also randomly assigned to humid chambers immediately after inoculation for $0,4,8,16,32$, and $64 \mathrm{~h}$ of LWD. The experiment was designed as a two-factor experiment (temperature and LWD) with six single-plant replications per treatment and was repeated once.

Humid chambers consisted of 30-liter transparent plastic bags placed inside growth chambers. About $50 \mathrm{ml}$ of sterile distilled water was sprayed over plastic surfaces inside each bag. Plants in pots were placed inside the bags, which were then inflated and sealed to prevent inoculated foliage from touching the bag. After removal from humid bags, plants were kept in the same chamber, and leaf surface drying time was then visually evaluated and added to the pre-assigned wetness periods to give total LWD. Drying times ranged from 20 to $60 \mathrm{~min}$ according to temperature.

Although there were no plant treatments at $40^{\circ} \mathrm{C}$, survival tests were carried out by transferring 0.5 -cm-diameter plugs of $C$. gossypii var. cephalosporioides from oatmeal agar to eight replicate plates of oatmeal agar and culturing at $40^{\circ} \mathrm{C}$ for $48 \mathrm{~h}$.

After removal from humid chambers, plants were inspected daily for symptom development. After the first symptoms appeared, lesions were counted every $48 \mathrm{~h}$ to determine disease severity (number of lesions per leaf area). When number of lesions ceased increasing in all treatments, the cotton plants were removed from growth chambers for severity evaluation. All leaves of each plant were detached, arrayed against a white background, and photographed with a digital camera. The total number of leaves of each plant was photographed separately. Digital images were later assessed with image analysis software to measure disease severity (Quant, v1.0.0.22, Federal University of Viçosa, Viçosa, MG, Brazil).

Disease efficiency (DE) was defined for each temperature $\times$ LWD combination as the ratio of the number of lesions that developed during an incubation treatment to the mean number of lesions that developed after inoculation under optimum temperature and LWD for lesion development.

DE data as a function of temperature and LWD were fitted with monomolecular, logistic, Gompertz, generalized beta, and Richards models. Additional models tested were functions of temperature and LWD separately, and three-dimensional (3D) response models that were a function of temperature and LWD using Table Curve (v2.03, Jandel Scientific, San Rafael, CA).

Models were compared based on (i) coefficient of determination $\left(R^{2}\right)>0.90$, (ii) mathematical simplicity and number of parameters, (iii) residual plots, and (iv) curve shape. For curve shape, models that predicted intervals below 0.0 (negative values) or had sudden alterations of trend or discontinuities were not considered, since most biological processes tend to be continuous and present gradual alterations in shape.

After testing several possible models on Table Curve (v2.03, Jandel Scientific) through regression analysis, a three-parameter equation was selected to describe DE as a function of LWD [DE = $f(\mathrm{LWD})]$ at each temperature tested. This model is presented in the Results section. The parameters $(a, b$, and $c)$ of this equation were individually fitted to models to define their variation across the range of temperatures $[\mathrm{a}, \mathrm{b}, \mathrm{c}=f(\mathrm{~T})]$. These functions were used to replace the original parameters of the DE equation, resulting in a three-dimensional response surface [DE $=f(\mathrm{LWD}, \mathrm{T})]$ that accounted for both LWD and temperature effects.

Field experiments. Field experiments were carried out in 2004, 2005, and 2006 at the experimental farm of the University of São Paulo, Piracicaba, SP, Brazil (latitude $22^{\circ} 42^{\prime}$ S; longitude $47^{\circ} 37^{\prime} \mathrm{W} ; 546 \mathrm{~m}$ altitude). The climate is subtropical humid with a dry winter; soil is a Hapludox with $30 \%$ clay, $34 \%$ silt, and $36 \%$ sand.

Cultivar Makina was also used for field experiments. In each growing season 32 subplots, four rows wide and $5 \mathrm{~m}$ long with an interrow spacing of $0.90 \mathrm{~m}$ and 10 plants per meter in each row, were initially established in November. A 1-m-long border of bare soil separated adjacent subplots within rows. In 2004 and 2005, 16 randomly selected subplots were inoculated 35 DAE by spraying an inoculum suspension $\left(10^{5}\right.$ conidia $\left.\mathrm{ml}^{-1}\right)$ at $2000 \mathrm{~h}$. This conidial concentration was determined in previous work (3) to be optimum for causing typical field symptoms. In 2006, inoculated subplots were subdivided into two groups of eight each; one group was inoculated at $35 \mathrm{DAE}$ and the second at 42 DAE. At 35 to 42 DAE, cotton plants were beginning to show the first floral buttons (squares). In each year, disease assessments were made weekly on five arbitrarily selected plants in each of the center two rows of each subplot, for a total of 10 plants per plot on each of 13 assessment dates per growing season.

In 2004, disease assessments were made following a scale previously developed in Brazil that was based on the appearance of different types of ramulosis symptoms, including lesions and morphological distortion: 1 = absence of symptoms; 2 = necrotic lesions in leaves or stems; 3 = apical meristem death; $4=$ apical meristem death and lateral shoot proliferation; and $5=$ shoot proliferation and stunting. In 2005 and 2006, a more quantitative scale was standardized to average area of a fully expanded cotton leaf $\left(0.36 \mathrm{~m}^{2}\right): 0=$ no lesions; $1=1$ to 10 lesions per plant $(1$ to 28 lesions per $\mathrm{m}^{2}$ of leaf); $2=11$ to 20 lesions per plant ( 29 to 55 lesions per $\mathrm{m}^{2}$ of leaf); $3=21$ to 30 lesions per plant (56 to 83 lesions per $\mathrm{m}^{2}$ of leaf); $4=31$ to 40 lesions per plant ( 84 to 112 lesions per $\mathrm{m}^{2}$ of leaf); and $5=41$ to 50 lesions per plant (113 to 141 lesions per $\mathrm{m}^{2}$ of leaf).

Leaf area and shoot dry weight were evaluated by destructive sampling of two plants per plot at 30,60, 90, and 120 DAE. After plants were sampled and all leaves were excised, leaf area was determined with a LI-COR Area Meter (Model LI-3000, LI-COR, Lincoln, NE).

Weather data were recorded hourly by a data logger (CR-10x, Campbell Scientific, Logan, UT) in the center of the experimental field after plant emergence. Weather data included temperature, relative humidity $(\mathrm{RH}), \mathrm{LWD}$, global solar radiation $(\mathrm{Qg})$, wind speed, and rainfall. Duplicate sensors for temperature, RH, and LWD were mounted between crop rows, at a height adjusted weekly to correspond to the upper third of the crop canopy (24). Flat, printed-circuit sensors (Model 237, Campbell Scientific) were used to measure LWD. All the sensors were treated with two coats of off-white latex paint, as suggested in previous studies (24), to increase the ability of the sensors to detect small amounts of wetness, and were installed facing south at $45^{\circ}$ to horizontal.

A disease favorability index was calculated for each day using the response surface equation based on temperature and LWD. In growth chamber trials, DE varied within the interval from 0 to 1 
over the 0 - to 64-h LWD range. However, the favorability index calculated from temperature and LWD (FI-tw) can vary only from 0 to 0.94 across a LWD range of 0 to $24 \mathrm{~h}$ on a daily time step. This happens because DE can reach the maximum of 0.94 in $24 \mathrm{~h}$ of LWD. Consequently, a correction of $6.38 \%$ (the ratio between "DE on $64 \mathrm{~h}$ " and "DE on $24 \mathrm{~h}$ " or 1.0/0.94) was applied to adjust the range scale from $0.00<\mathrm{DE}<0.94$ to $0.00<$ FI-tw $<1.00$. The LWD for a specific day was based on measurements during the continuous 24-h interval from $1200 \mathrm{~h}$ on a given day to $1200 \mathrm{~h}$ the next day. Temperature was averaged for the same 24-h periods and favorability index was calculated for the same time step. Average temperature was also calculated for daily periods that included only wet hours.

Weekly DDR was compared with weather variables from 14 to 70 days after inoculation (DAI), during the vegetative growth period for cotton. Because plants were artificially inoculated, disease rates from 0 to 14 DAI were not included in the analysis. Rates obtained after 70 DAI (105 DAE) were also excluded, as this was a period of decreased vegetative growth.

Relationships between weekly disease development rates (DDR) and weather variables were averaged or totaled over 7 days (weekly scale) as independent variables and assessed by regression analysis. The following were considered as explanatory variables: average temperature (noon to noon), average temperature during wetness periods, $\mathrm{RH}$, global solar radiation, average wind speed, daily maximum wind speed, LWD, rainfall, favorability index based on LWD and daily average temperature (FItw), and favorability index based on LWD and temperature during wet periods (FI-wtw).

Regressions were also examined for time lags of 1 to 9 days. DDR during a given 7-day interval was compared to the weather
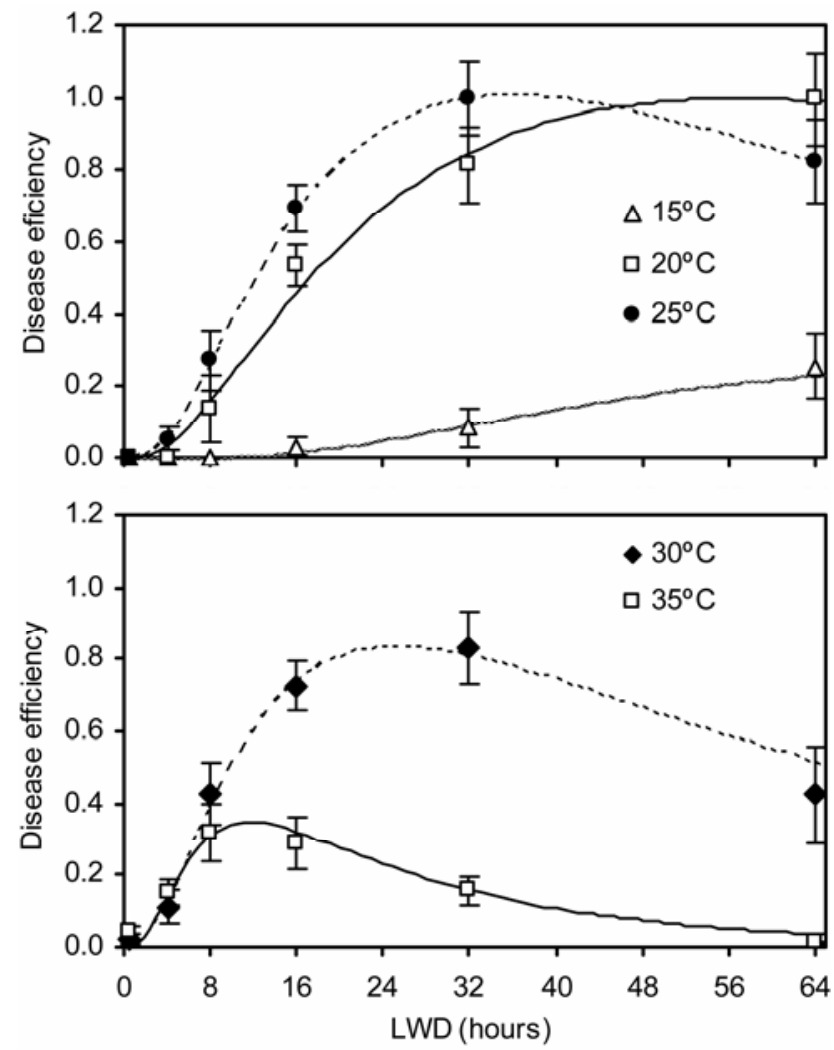

Fig. 1. Disease efficiency of ramulosis of cotton that developed after treatment of inoculated plants at $15,20,25$, and $30^{\circ} \mathrm{C}$ for leaf wetness duration (LWD) periods ranging from 0 to $64 \mathrm{~h}$. Dots represent the average per treatment and vertical bars indicate confidence interval at $95 \%$. The lines represent the best model for each temperature, adjusted as a function of LWD. Dots at $35^{\circ} \mathrm{C}$ are model estimates as function of temperature and vertical bars indicate confidence interval at $95 \%$. variables averaged over the same period as well as to preceding periods varying in duration from 1 to 9 days.

\section{RESULTS}

Controlled environment experiments. Ramulosis symptoms appeared on cotton plants when temperatures ranged from 15 to $30^{\circ} \mathrm{C}$. Inoculum drying time after plant removal from wet chambers was approximately $1 \mathrm{~h}$ at $15^{\circ} \mathrm{C}, 40 \mathrm{~min}$ at $20^{\circ} \mathrm{C}, 25 \mathrm{~min}$ at $25^{\circ} \mathrm{C}$, and $20 \mathrm{~min}$ at $30^{\circ} \mathrm{C}$. Plants that were not incubated in a wet chamber after inoculation showed no symptoms at 15,20 , or $25^{\circ} \mathrm{C}$. Plants maintained in the wet chamber for $4 \mathrm{~h}$ developed no symptoms at 15 or $20^{\circ} \mathrm{C}$, whereas those kept for $8 \mathrm{~h}$ in wet chambers were asymptomatic only at $15^{\circ} \mathrm{C}$.

The maximum disease severity, 0.26 lesions per $\mathrm{cm}^{2}$ of leaf area, used as a reference for quantifying DE, was observed at $25^{\circ} \mathrm{C}$ and $32 \mathrm{~h}$ of LWD. Average DE was similar at 20, 25, and $30^{\circ} \mathrm{C}$, but decreased sharply at lower or higher temperatures (Fig. 1). Average DE was $0.06,0.41,0.47$, and 0.42 at $15,20,25$, and $30^{\circ} \mathrm{C}$, respectively. C. gossypii var. cephalosporioides did not grow when cultures were incubated for $4 \mathrm{~h}$ at $40^{\circ} \mathrm{C}$. Assuming that $\mathrm{DE}$ at $40^{\circ} \mathrm{C}$ was zero, $\mathrm{DE}$ at $35^{\circ} \mathrm{C}$ was interpolated based on the model as 0.16 .

Ramulosis incubation period varied according to temperature and LWD (Fig. 2). When averaged across the six wetness periods, the incubation period was approximately 15 days at $15^{\circ} \mathrm{C}, 11$ days at $20^{\circ} \mathrm{C}, 10$ days at $25^{\circ} \mathrm{C}$, and 9 days at $30^{\circ} \mathrm{C}$.

Incubation period decreased as LWD increased. This trend was particularly evident from 4 to $16 \mathrm{~h}$ of LWD, whereas little response was noted from 32 to $64 \mathrm{~h}$ of LWD.

The disease response surface model that provided the best fit was based on an exponential model relating disease and LWD, as defined by equation 1 .

$$
\left.\mathrm{DE}=a \times e^{\left\{-0.5\left[\frac{\mathrm{Ln}(\mathrm{LWD} / b)}{c}\right]^{2}\right.}\right\}
$$

In this model, DE is disease efficiency and $a, b$, and $c$ are parameters that represent the effect of temperature. Table 1 presents the values of $a, b$, and c obtained by adjustment of equation 1 for each temperature tested. In this model, parameter a represents the maximum $\mathrm{DE}$ at a given temperature; thus, $\mathrm{a}$ is a temperature function, $b$ is a value of optimum LWD at which a occurs, and c indicates indirectly the degree to which disease is dependent on LWD. A high value of $\mathrm{c}$ corresponds to disease development at a similar rate across a broad range of LWD,

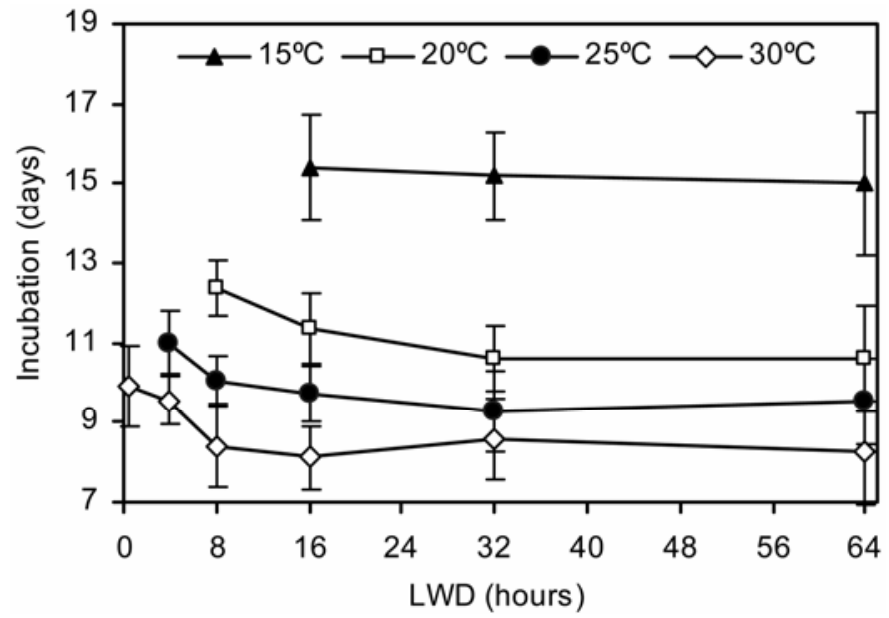

Fig. 2. Ramulosis incubation period of cotton ramulosis at $15,20,25$, and $30^{\circ} \mathrm{C}$ for 0 to $64 \mathrm{~h}$ of leaf wetness duration (LWD). Vertical bars represent the confidence interval for $95 \%$ probability. 
whereas a low value corresponds to a DDR that is more sharply influenced by LWD. In addition, $\mathrm{b}$ and $\mathrm{c}$ varied with temperature.

Regression models for $\mathrm{a}, \mathrm{b}$, and $\mathrm{c}$ were examined as a function of temperature (Fig. 3), resulting in a response surface model in which each parameter $(a, b$, and $c)$ was described by the following regression equations:

$$
\begin{gathered}
\mathrm{a}=0.000291 T^{3}-0.0292 T^{2}+0.89 T-7.5 \\
\mathrm{~b}=-0.0078 T^{3}+0.768 T^{2}-26.98 T+353 \\
\mathrm{c}=-0.001 T^{2}+0.043 T+0.4984
\end{gathered}
$$

The final response surface model is a function of equations 1 , 2, 3, and 4 (Fig. 4). Based on this model, for $24 \mathrm{~h}$ of LWD, maximum DE occurred at $27^{\circ} \mathrm{C}$.

Field experiments. In 2005, the qualitative disease rating scale indicated that the most rapid increase in ramulosis occurred

TABLE 1. Parameters for the exponential model of disease efficiency as a function of leaf wetness duration, $\mathrm{DE}=\mathrm{a}\left(e^{\left\{-0.5[\operatorname{Ln}(\mathrm{LWD} / \mathrm{b}) / \mathrm{c}]^{\wedge} 2\right\}}\right)$ (equation 1$)$

\begin{tabular}{lcccccc}
\hline & \multicolumn{5}{c}{ Temperature $^{\circ} \mathrm{C}$} \\
\cline { 2 - 5 } Parameter & 15 & 20 & 25 & 30 & 40 & SE \\
\hline $\mathrm{a}^{\mathrm{x}}$ & 0.27 & 1.00 & 1.00 & 0.83 & 0.01 & 0.048 \\
$\mathrm{~b}^{\mathrm{y}}$ & 95.0 & 57.0 & 36.0 & 26.0 & 2.00 & 0.041 \\
$\mathrm{c}^{\mathrm{z}}$ & 0.92 & 0.96 & 0.93 & 0.90 & 0.60 & 0.053 \\
$R^{2}$ & 0.99 & 0.99 & 1.00 & 0.98 & 1.00 & \\
\hline
\end{tabular}

${ }^{x}$ Parameter a represents the maximum disease efficiency at a given temperature.

y Parameter $b$ is a value of optimum leaf wetness duration (LWD) at which a occurs.

${ }^{z}$ Parameter $\mathrm{c}$ indicates indirectly the degree to which disease is dependent on LWD. A high value of c corresponds to a disease that develops at a similar rate across a broad range of LWD, whereas a low value corresponds to a disease development rate that is more strongly influenced by LWD. In addition, $\mathrm{a}, \mathrm{b}$, and $\mathrm{c}$ are functions of temperature.
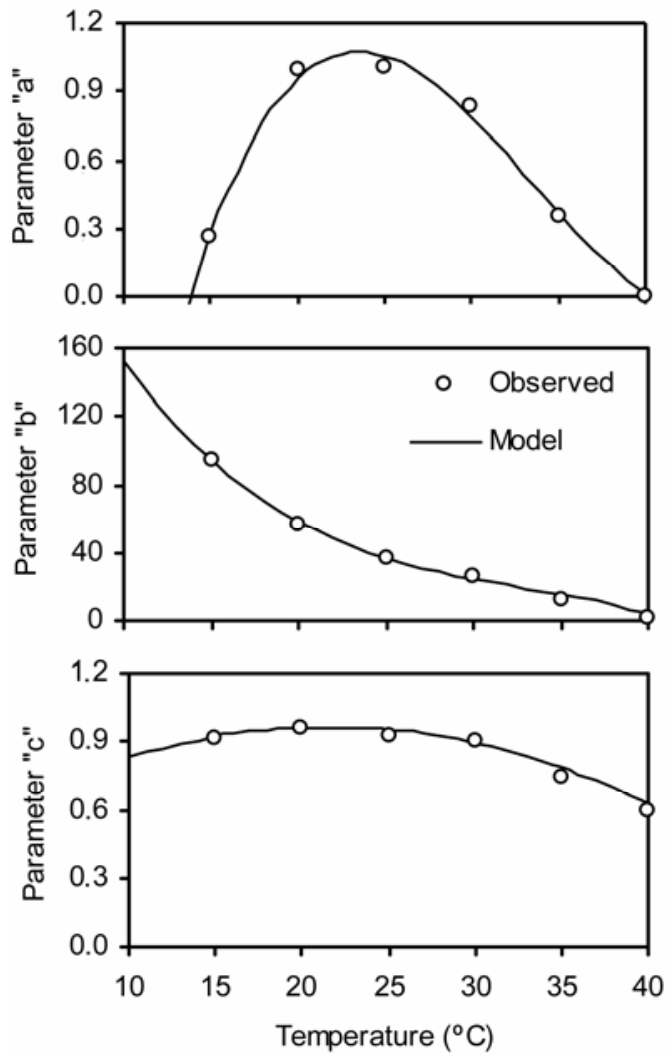

Fig. 3. Parameters a, b, and c from equation 1 as functions of temperature in growth chamber experiments on ramulosis of cotton. between 21 and 42 DAI, whereas the quantitative scale showed that disease progress was most rapid between 35 and 49 DAI (Table 2). Between 49 and 56 DAI, a decrease in disease intensity was observed when using the quantitative scale, whereas the qualitative scale indicated a slight increase in disease intensity. These differences indicated that the qualitative scale, although useful for loss estimation, may not be well suited for epidemiological studies.

Using the DE model obtained from growth chamber experiments (equation 1) with the correction factor of $6.38 \%$ for field conditions (changing range scale from $0.00<\mathrm{DE}<0.94$ to $0.00<$ FI-tw $<1.00)$, the resulting favorability index was defined as

$$
\text { FI- tw } \left.=1.0638 \times a \times e^{\left\{-0.5\left[\frac{\operatorname{Ln}(\mathrm{LWD} / b)}{c}\right]^{2}\right.}\right\}
$$

When this model was applied to field results from 2004, 2005, and 2006, FI-tw varied from 0.01 to 0.83 . Variation in FI-tw was similar to that in LWD, since the magnitude of LWD variation was greater than that of temperature; the latter typically varied between 20 and $30^{\circ} \mathrm{C}$, a range in which disease development is not much affected (Fig. 5).

Weekly DDR observed in the field was most closely correlated to the favorability index accumulated 6 days earlier. For example, DDR calculated between 14 and 21 days after inoculation had the highest correlation with FI-tw accumulated 8 to 15 days after inoculation. This time lag in response was similar for other variables analyzed separately, such as mean temperature, mean temperature during wetness periods, LWD, and cumulative rainfall, varying from 5 to 7 days depending on the variable.

In general, FI-tw and DDR data were defined by a sigmoid curve with a 6-day time lag. Some of the data did not fit this trend, however, resulting in relatively poor fit of an exponential model $\left(\mathrm{b}=0.92 ; R^{2}=0.27 ;\right.$ residue $\left.=1.91\right)$ :

$$
\mathrm{DDR}=\frac{0.52}{1+e^{\left[\frac{-(\mathrm{FI}-\mathrm{tw}-1.65)}{0.3}\right]}}
$$

Ramulosis growth rate was approximately 0 when cumulative weekly FI-tw was between 0 and 1 , increased between FI-tw

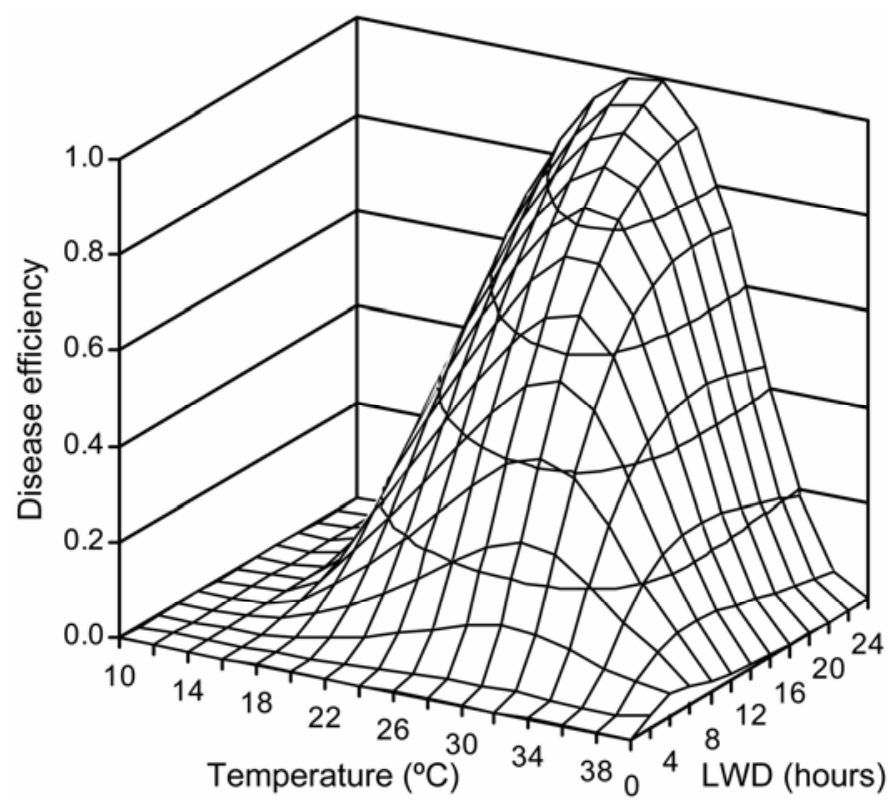

Fig. 4. Response surface of disease efficiency of ramulosis of cotton as a function of temperature and leaf wetness duration (LWD) treatments in growth chamber experiments. 
values of 1 and 2.5, and then reached an asymptote (Fig. 6). Maximum DDR was 0.52 when FI-tw was 1.65 , at the inflection point of the curve.

A model relating ramulosis DDR to cumulative rainfall (Fig. 7) showed a determination coefficient of 0.91 and was defined as

$$
\operatorname{DDR}=0.58\left\{e^{-0.5\left[(\operatorname{Ln}(\operatorname{Rain} / 54) / 0.305)^{2}\right]}\right\}+0.0122
$$

Unlike the model that related ramulosis growth rate to FI-tw, no outlier points were observed in the rainfall model. Ramulosis development rate increased slowly until cumulative rainfall reached $30 \mathrm{~mm}$, then increased exponentially until approximately $60 \mathrm{~mm}$ (Fig. 7). In comparison with the model for ramulosis growth rate and FI-tw, the rainfall model was deemed superior based on the goodness of fit $\left(\mathrm{b}=0.96 ; R^{2}=0.91\right.$; residue $\left.=0.85\right)$. Highlighted rain ranges on Figure 7 represent its corresponding levels of risk where 0 to $20 \mathrm{~mm}$ per week stands for very low risk, or a DDR close to $0 ; 20$ to $40 \mathrm{~mm}$ per week corresponds to low risk or $0<$ $\mathrm{DDR} \leq 0.2 ; 40$ to $70 \mathrm{~mm}$ per week corresponds to a high risk situation or $0.4<\mathrm{DDR} \leq 0.6$; and 70 to $90 \mathrm{~mm}$ per week result in medium risk or $0.2<\mathrm{DDR} \leq 0.4$.

\section{DISCUSSION}

The results constitute the first quantitative evidence relating ramulosis disease development in cotton to environmental conditions. Temperature and wetness duration were clearly important factors in disease development over a wide range of controlled conditions, since a high proportion of the variability of mean disease severity was accounted for by these variables. On the other hand, under field conditions, the variation in temperature range remained close to the optimum. As a result, disease severity in the field was more responsive to wetness duration and cumulative rainfall than temperature.

In the controlled environment experiments, the term disease establishment is used to describe the outcome of primary infection only (monocycle), since we assumed initially that ramulosis would exhibit minimum lesion expansion and disease severity could increase more by subsequent lesion appearance than by lesion expansion. Thus, the FI-tw model is strictly an infection model, avoiding the error associated with confounding infection appearance and lesion growth. This might explain the fact that under field conditions, FI-tw presents positive correlation with DDR only when cumulative rainfall is in the range of 30 to $60 \mathrm{~mm}$. Above or below this range, dispersion of this splash- dispersed pathogen seems to be compromised by lack or excess of rain, respectively.

Using the adjusted equation, the optimum temperature for ramulosis establishment was $27^{\circ} \mathrm{C}$ compared with $17^{\circ} \mathrm{C}$ for C. lindemuthianum on bean (7), $24^{\circ} \mathrm{C}$ for $C$. orbiculare on watermelon (16), and 23 to $27^{\circ} \mathrm{C}$ for $C$. acutatum on strawberry (13).

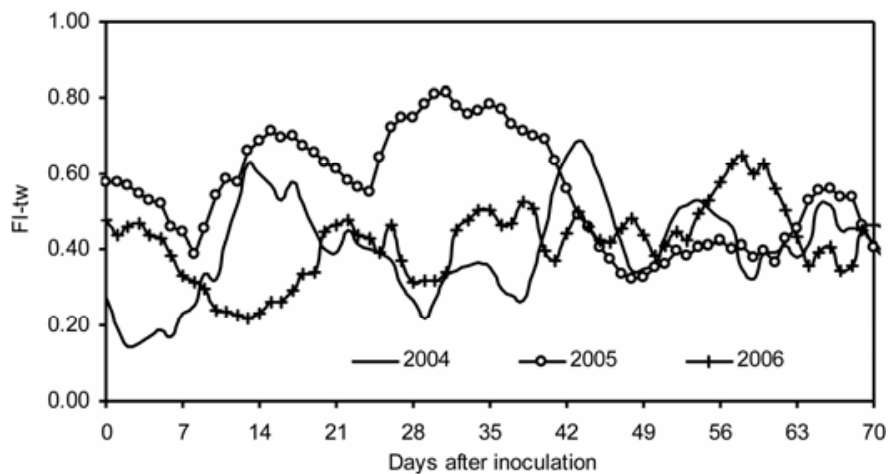

Fig. 5. Seven-day running average favorability index of cotton ramulosis for temperature and wetness (FI-tw) from 0 to 70 days after inoculation in field experiments during 2004, 2005, and 2006 at Piracicaba, SP, Brazil.

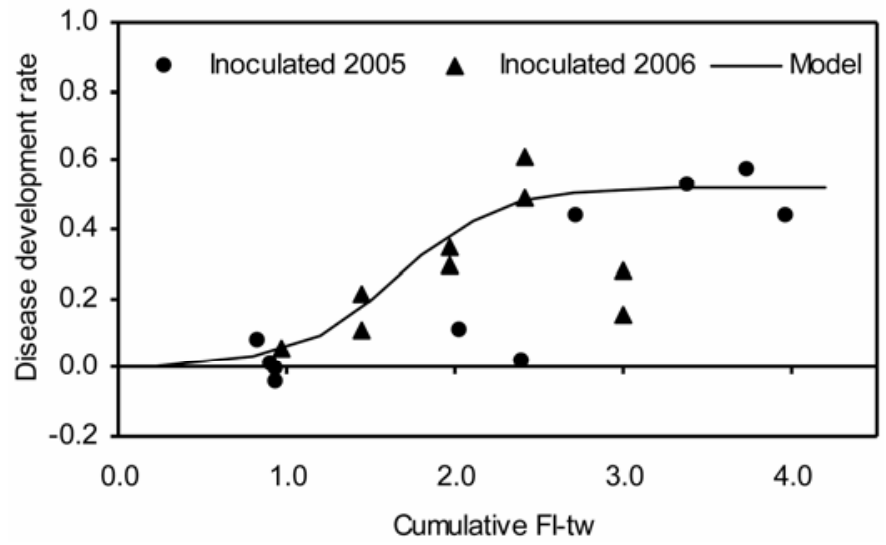

Fig. 6. Development rate of ramulosis disease of cotton as a function of the cumulative favorability index of cotton ramulosis for temperature and wetness (FI-tw) 6 days prior to the date of disease assessment, from field experiments during 2005 and 2006 at Piracicaba, SP, Brazil.

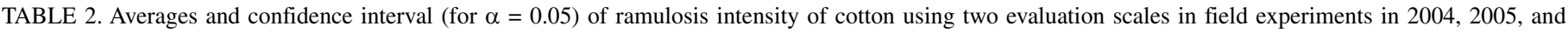
2006 at Piracicaba, SP, Brazil

\begin{tabular}{|c|c|c|c|c|c|c|c|c|c|c|c|c|}
\hline \multirow[b]{2}{*}{ Rating scale } & \multirow[b]{2}{*}{ Year } & \multicolumn{10}{|c|}{ Days after emergence ${ }^{\mathrm{x}}$} & \multirow[b]{2}{*}{ AUDPC } \\
\hline & & 42 & 49 & 56 & 63 & 70 & 77 & 84 & 91 & 98 & 105 & \\
\hline \multirow[t]{8}{*}{ Qualitative } & 2004 & 1.15 & 1.73 & 1.78 & 1.96 & 2.17 & 2.34 & 2.73 & 3.14 & 3.63 & 4.09 & 144.6 \\
\hline & & \pm 0.10 & \pm 0.15 & \pm 0.16 & \pm 0.19 & \pm 0.23 & \pm 0.26 & \pm 0.33 & \pm 0.36 & \pm 0.43 & \pm 0.47 & \\
\hline & 2005 & 1.22 & 1.58 & 1.75 & 2.31 & 3.08 & 3.86 & 4.03 & 4.22 & 4.25 & 4.25 & 184.9 \\
\hline & & \pm 0.22 & \pm 0.24 & \pm 0.29 & \pm 0.40 & \pm 0.44 & \pm 0.34 & \pm 0.29 & \pm 0.23 & \pm 0.23 & \pm 0.23 & \\
\hline & $2006^{\mathrm{Z}}$ & 1.16 & 1.81 & 2.00 & 2.50 & 2.78 & 3.19 & 3.44 & 3.91 & 4.16 & 4.16 & 174.8 \\
\hline & (i) & \pm 0.13 & \pm 0.27 & \pm 0.26 & \pm 0.48 & \pm 0.48 & \pm 0.46 & \pm 0.42 & \pm 0.36 & \pm 0.31 & \pm 0.31 & \\
\hline & $2006^{\mathrm{z}}$ & - & 1.13 & 1.50 & 1.56 & 1.97 & 2.50 & 2.78 & 3.00 & 3.53 & 3.59 & 125.2 \\
\hline & (ii) & & \pm 0.12 & \pm 0.18 & \pm 0.17 & \pm 0.22 & \pm 0.23 & \pm 0.29 & \pm 0.33 & \pm 0.32 & \pm 0.30 & \\
\hline \multirow[t]{7}{*}{ Quantitative } & & & & & & & & & & & & \\
\hline & 2005 & 0.28 & 0.69 & 1.00 & 1.53 & 1.69 & 2.67 & 3.83 & 3.67 & 3.64 & 3.92 & 142.3 \\
\hline & & \pm 0.24 & \pm 0.25 & \pm 0.32 & \pm 0.35 & \pm 0.34 & \pm 0.31 & \pm 0.25 & \pm 0.23 & \pm 0.19 & \pm 0.17 & \\
\hline & $2006^{z}$ & 0.31 & 1.09 & 1.16 & 1.28 & 1.66 & 2.47 & 2.84 & 2.97 & 2.97 & 2.97 & 121.6 \\
\hline & (i) & \pm 0.26 & \pm 0.40 & \pm 0.35 & \pm 0.38 & \pm 0.42 & \pm 0.45 & \pm 0.37 & \pm 0.39 & \pm 0.39 & \pm 0.39 & \\
\hline & $2006^{z}$ & - & 0.16 & 0.59 & 0.72 & 0.97 & 1.56 & 2.00 & 2.13 & 2.22 & 2.22 & 77.0 \\
\hline & (ii) & & \pm 0.16 & \pm 0.23 & \pm 0.28 & \pm 0.28 & \pm 0.26 & \pm 0.30 & \pm 0.33 & \pm 0.35 & \pm 0.35 & \\
\hline
\end{tabular}

x Inoculation occurred 35 days after emergence (DAE).

y Area under disease progress curve within 14 to 70 days after inoculation.

${ }^{\mathrm{z}}$ In 2006, one treatment was inoculated 35 DAE (i) and the other at 42 DAE (ii). 
The relationship of temperature with minimum LWD required for infection was similar to that on Colletotrichum spp. affecting cucumber (30), Xanthium spinosum (15), and bean (7). However, few other studies have characterized patterns of disease development for LWD longer than $24 \mathrm{~h}$. Reduction of disease severity in the 64-h LWD treatment could potentially have been caused by inoculum mortality due to microbial activity in the wet bag, but we have no experimental evidence to support or refute this hypothesis. There are indications on literature that fungi and bacteria are able to antagonize fungal plant pathogens in similar situations (2).

Although ramulosis establishment is influenced by both temperature and LWD, it is likely that, in field environments of São Paulo State, epidemics may be more influenced by LWD than temperature, because temperatures during the growing season generally fall within the optimum range for this pathogen. Average temperature during the experiments was $24^{\circ} \mathrm{C}$. During the 2004, 2005, and 2006 growing seasons in Piracicaba, for example, temperature was $<15^{\circ} \mathrm{C}$ only $15 \%$ of the time and $>30^{\circ} \mathrm{C}$ only $8 \%$ of the time.

To control ramulosis epidemics, Brazilian growers start applying fungicides when symptom severity reaches $2 \%$. This threshold is usually reached within 3 weeks after emergence. After that, a calendar-based schedule is followed in which fungicides are applied four to five times per crop cycle at intervals of 4 weeks. If increased severity level is detected at any time, the interval between applications is reduced to 3 weeks, and sometimes 2 weeks. In some cases, as many as eight fungicide sprays are applied in a growing season. Considering that weather conditions are not taken in to account by this strategy, there is a potential for spray savings using a weather-based warning system.

Colletotrichum spp. are known to be favored by rainfall, particularly because their conidia are dispersed by rain splash. Despite the weaker relation of DDR with FI-tw than with rainfall, results from the controlled environment trials explain an important part of the environmental biology of ramulosis. Models produced in controlled environments cannot always account for key environmental variables in the field (27), such as rainfall. In the FI-tw model, for example, two of four outliers points were associated with periods of intense rainfall (about $90 \mathrm{~mm}$ per week), whereas the two others occurred under low rainfall conditions ( $<30 \mathrm{~mm}$ per week).

Discrepancies between the scales were observed. Some reduction in average severity over time occurred with the quantitative scale, resulting in negative DDR. This decrease may have been due to increased vegetative growth of plants, resulting in a decrease in the average number of lesions per average leaf. The

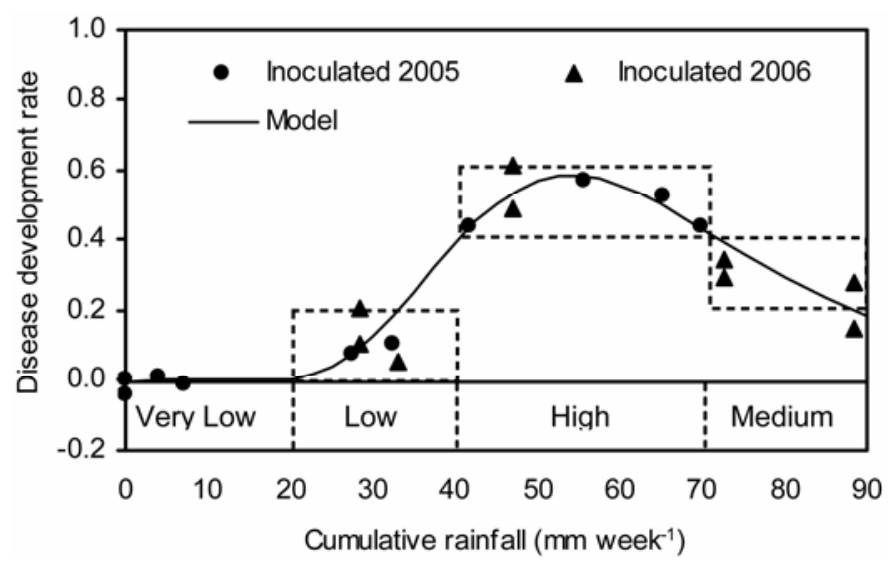

Fig. 7. Weekly disease development rate of ramulosis of cotton as a function of cumulative rainfall during the 6-day period preceding disease assessment, in field experiments during 2005 and 2006 at Piracicaba, SP, Brazil. Boxes identify categorical levels of epidemic risk. qualitative scale sometimes increased during the same periods that the quantitative scale decreased, because development of lateral shoots and stunting dictates a rating change from 3 to 4 or 4 to 5 , respectively, affecting disease intensity even without the appearance of new lesions. For this reason, the quantitative scale should be preferred as a more accurate index of DDR.

Although information about ramulosis epidemiology is scant, many reports link rain events to epidemics caused by Colletotrichum spp. in a range of crops $(3,4,9,12,14,18,26,31)$. Rainfall and overhead irrigation are important dissemination factors, even contributing to dissemination of pathogens typically dispersed by wind (9), but are especially important to dissemination of conidia generated in water-soluble mucilage, such as those of Colletotrichum spp. (18).

The relationship between DDR and rainfall, with positive or negative correlation depending on the amount of precipitation, illustrates clearly that prolonged LWD associated with rainfall does not exert a uniform impact on disease development. Maximum infection occurred at an intermediate amount of cumulative rainfall (about $60 \mathrm{~mm} /$ week). Heavier rainfall apparently washed conidia off leaves, thereby suppressing DDR. Rain intensity can have a positive, negative, or neutral impact on new plant infections resulting from pathogen dispersal $(14,20)$. This contrasting response for different ranges of accumulated rain suggests that a categorical approach is a logical summarization for the continuous model, especially if considered for practical applications. Studies quantifying weather effects on occurrence of $C$. falcatum in sugar cane (12), C. acutatum in Citrus spp. (31), and $C$. gloeosporioides in Stylosanthes scabra (4) found that number of days with rain and rain intensity best explained changes in disease development.

Development of a forecaster for minimizing unnecessary fungicide could yield significant benefits for growers of this economically important crop in Brazil. The models developed in this research provide a foundation for development of a weather-based disease forecaster for scheduling fungicide applications. Decision rules based on cumulative weather events can be determined from field experiments, increasing or decreasing the spray interval based on lower or higher predicted DDR. Further studies also should determine whether prediction can be improved with a temperature-LWD factor added to the rainfall model.

\section{LITERATURE CITED}

1. Agrios, G. N. 1997. Environmental effects on disease development. Pages 143-172 in: Plant Pathology. 4th ed. G. N. Agrios, ed. Academic Press, San Diego.

2. Artursson, V. 2005. Bacterial-fungal interactions highlighted using microbiomics: Potential application for plant growth enhancement. Acta Universitatis Agriculturae Sueciae. Swedish University of Agricultural Sciences, Uppsala, Sweden.

3. Carvalho, L. P., Carvalho, J. M. F. C., Lima, E. F., and Cavalcante, F. B. 1981. Influence of conidia concentration in the pathogenicity of Colletotrichum gossypii var. cephalosporioides A.S. Costa and evaluation of cultivars and lineages of cotton to ramulosis. Fitopatol. Bras. 6:395-402. (in Portuguese)

4. Chakraborty, S., and Billard, L. 1995. Quantitative relationships between Colletotrichum gloeosporioides infection of Stylosanthes scabra and weather under field conditions. Plant Pathol. 44:63-72.

5. Cia, E., and Fuzatto, M. G. 1999. Cotton disease management. Pages 121131 in: The Cotton Crop. E. Cia, E. C. Freire, and W. J. Santos, eds. Piracicaba, Potafos, SP, Brazil. (in Portuguese)

6. Cia, E., Gridi-Papp, I. L., Chiavegato, E. J., Sabino, N. P., Kondo, J. I., Pizzinato, M. A., Bortoletto, N., and Carvalho, L. H. 2001. Cotton breeding in São Paulo State: Obtention of the genotype IAC 21. Bragantia, Campinas, SP, Brazil. 60:9-17. (in Portuguese)

7. Dalla Pria, M., Amorim, L., and Bergamin Filho, A. 2003. Quantification of monocyclic components of the common bean anthracnose. Fitopatol. Bras. 28:401-407. (in Portuguese)

8. Evans, K. J., Nyquist, W. E., and Latin, R. X. 1992. A model based on temperature and leaf wetness duration for establishment of Alternaria leaf blight of muskmelon. Phytopathology 82:890-895. 
9. Fitt, B. D. L., McCartney, H. A., and Walklate, P. J. 1989. The role of rain in dispersal of pathogen inoculum. Ann. Rev. Phytopathol. 27:241-270.

10. Huber, L., and Gillespie, T. J. 1992. Modeling leaf wetness in relation to plant disease epidemiology. Ann. Rev. Phytopathol. 30:553-577.

11. ICAC (International Cotton Advisory Committee). 2002. Cotton world statistics. Secretariat of the International Cotton Advisory Committee, Washington.

12. Kumar, A., Satyavir, and Niwas, R. 1998. Prediction of red rot Colletotrichum falcatum incidence in sugarcane under field conditions using climatic variables. Pages 333-335 in: International Congress of Phytopathology. Academic Press, Edinburgh.

13. Leandro, L. F. S., Gleason, M. L., Nutter, F. W., Jr., Wegulo, S. N., and Dixon, P. M. 2003. Influence of temperature and wetness duration on conidia and appressoria of Colletotrichum acutatum on symptomless strawberry leaves. Phytopathology 93:513-520.

14. Madden, L. V., Yang, X., and Wilson, L. L. 1996. Effects of rain intensity on splash dispersal of Colletotrichum acutatum. Phytopathology 86:864874.

15. McRae, C. F., and Auld, B. A. 1988. The influence of environmental factors on anthracnose of Xanthium spinosum. Phytopathology 78:1182-1186.

16. Monroe, J. S., Santini, J. B., and Latin, R. 1997. A model defining the relationship between temperature and leaf wetness duration, and infection of watermelon by Colletotrichum orbiculare. Plant Dis. 81:739-742.

17. Monteiro, J. E. B. A., Sentelhas, P. C., and Chiavegato, E. J. 2006. Microclimate and ramulosis occurrence in a cotton crop under three plant population densities in Southern Brazil. Agriscientia 23:45-53.

18. Nicholson, R. L., and Moraes, W. B. C. 1980. Survival of Colletotrichum graminicola: Importance of the spore matrix. Phytopathology 70:255-261.

19. Paiva, F. A., Asmus, G. L., and Araújo, A. E. 2001 Diseases. Pages 245272 in: Cotton: Production Technology. Embrapa Agropecuária Oeste, Brazil. (in Portuguese)

20. Pedersen, E. A., Morrall, R. A. A., McCartney, H. A., and Fitt, B. D. L. 1994. Dispersal of conidia of Ascochyta fabae f. sp. lentis from infected lentil plants by simulated wind and rain. Plant Pathol. 43:50-55.
21. Pfender, W. F. 2002. Prediction of stem rust infection favorability by means of degree-hour wetness duration for perennial ryegrass seed crops. Phytopathology 93:467-477.

22. Rotem, J., and Palti, J. 1969. Irrigation and plant disease. Ann. Rev. Phytopathol. 7:267-288.

23. Santos, G. R. 1993. Cotton ramulosis progress and transmission of Colletotrichum gossypii South. var. cephalosporioides Costa by seeds. UFV, Viçosa, MG, Brazil. (in Portuguese)

24. Sentelhas, P. C., Gillespie, T. J., Gleason, M. L., Monteiro, J. E. B. A., and Helland, S. T. 2004. Operational exposure of leaf wetness sensors. Agric. For. Meteorol. 126:59-72.

25. Silva-Mann, R., Salgado, K. C. C., Vieira, M. G. G. C., and Machado, J. C. 2002. Genetic variability of Colletotrichum complex associated with cotton seeds, by using molecular markers and plant inoculation. Fitopatol. Bras. 27:27-32. (in Portuguese)

26. Steadman, O. J. 1980. Splash droplet and spore dispersal studies in field beans (Vicia faba L.). Agric. Meteorol. 21:111-127.

27. Sutton, J. C. 1988. Predictive value of weather variables in the epidemiology and management of foliar diseases. Fitopatol. Bras. 13:305312.

28. Teixeira, H. 1995. Colletotrichum gossypii South in cotton (Gossypium hirsutum L.) seeds: Transmission and control. ESAL, Lavras, MG, Brazil. (in Portuguese)

29. Thompson, D. C., and Jenkins, S. F. 1985. Effect of temperature, moisture, and cucumber cultivar resistance on lesion size increase and conidial production by Colletotrichum lagenarium. Phytopathology 75:828-832.

30. Timmer, L. W., and Zitko, S. E. 1996. Evaluation of a model for prediction of postbloom fruit drop of citrus. Plant Dis. 80:380-383.

31. Venus, J. C., and Causton, D. R. 1979. Plant growth analysis: The use of the Richards function as an alternative to polynomial exponentials. Ann. Bot. 43:623-632.

32. Watkins, G. M. (ed.) 1981. Compendium of Cotton Diseases. American Phytopathological Society, St. Paul, MN. 